\title{
UMA REFLEXÃO SOBRE O PROCEDIMENTO ESPECIAL DO MANDADO DE SEGURANÇA: É POSSÍVEL UMA SOLUÇÃO DIALÓGICA PARA A MELHOR CONCRETIZAÇÃO DE DIREITOS FUNDAMENTAIS? ${ }^{1}$
}

\section{A REFLECTION ON THE SPECIAL PROCEDURE OF THE WRIT OF}

\section{MANDAMUS: IS IT POSSIBLE A DIALOGICAL SOLUTION FOR THE BEST REALIZATION OF FUNDAMENTAL RIGHTS?}

Sandoval Alves da Silva Doutor e mestre em Direito pela Universidade Federal do Pará (UFPA), na linha de pesquisa sobre constitucionalismo, democracia e direitos humanos. Procurador do trabalho lotado na Procuradoria Regional do Trabalho da 8. ${ }^{a}$ Região, Vice-Procurador Chefe da 8. ${ }^{a}$ Região. Professor da UFPA, na graduação e na pós-graduação em Direito. Membro da International Association of Procedural Law (IAPL), membro do Instituto Ibero-Americano de Direito Processual (IIDP). Associado da Associação Norte e Nordeste de Professores de Processo (ANNEP). Ex-coordenador nacional da Coordenadoria Nacional de Promoção de Igualdade de Oportunidades e Eliminação da Discriminação no Trabalho (Coordigualdade), ex-professor de Direito Financeiro e Orçamento Público, ex-procurador do Estado do Pará, exassessor da Auditoria Geral do Estado do Pará e ex-analista de controle externo do Tribunal de Contas do Estado do Pará. E-mail: sandovalalves8@gmail.com. Belém, PA. https://orcid.org/0000-0002-1795-2281.

\footnotetext{
${ }^{1}$ Artigo recebido em 11/06/2020 e aprovado em 28/10/2020.
} 
Thiago Vasconcellos Jesus

Mestrando em Direito pela Universidade Federal do Pará (UFPA). Especialização em Direito Público pela Universidade Gama Filho (UGF). Graduação em Direito pela UFPA. Procurador do Estado do Pará. Ex-procurador do Estado de Minas Gerais, ex-servidor do Ministério Público da União (MPU), na Procuradoria da República no Estado do Pará (PR/PA). Professor de Processo Civil II licenciado da Escola Superior Madre Celeste (Esmac), ex-professor de Processo Civil do curso Libbre Educacional. E-mail: thiagojesus1@hotmail.com. Belém,

PA. https://orcid.org/0000-0001-5186-9206.

Victor Sales Pinheiro Doutor em Filosofia pela Universidade Estadual do Rio de Janeiro (UERJ). Mestre em Filosofia pela Pontíficia Universidade Católica (PUC) do Rio de Janeiro. Graduado em Direito no Centro Universitário do Pará (Cesupa). Professor da graduação e da pós-graduação da Universidade Federal do Pará (UFPA) e do Cesupa. Coordenador dos Grupos de Pesquisa (CNPq) "Tradição da Lei Natural" e “Razão Pública, Secularização e Lei Natural”. E-mail: vvspinheiro@yahoo.com.br. Belém, PA. https://orcid.org/0000-0003-1908-9618.

RESUMO: Há relação entre justiça, argumentação racional e democracia deliberativa. O neoconstitucionalismo e o formalismo valorativo demonstram a importância da tutela efetiva dos direitos fundamentais. Deve-se priorizar soluções definitivas como instrumento de acesso à ordem jurídica justa, com a exposição das argumentações plurais e exercício da persuasão racional. A ação constitucional do mandamus objetiva afastar possíveis atos ilegais, inviabilizada a dilação probatória. Analisou-se a jurisprudência do TJPA sob o 
ângulo do reconhecimento do formalismo valorativo e quando constatadas eventuais irregularidades processuais no Mandado de Segurança. Concluiu-se sobre fundamentos legais e filosóficos do diálogo para avanço procedimental no MS.

PALAVRAS-CHAVE: Acesso à justiça. Mandado de segurança. Procedimento dialógico. Racionalidade persuasiva. Direitos fundamentais.

ABSTRACT: There is a relationship between justice, rational argument and deliberative democracy. Neoconstitutionalism and evaluative formalism demonstrate the importance of effective protection of fundamental rights. Definitive solutions should be prioritized as an instrument of access to the just legal order, with the presentation of plural arguments and the exercise of rational persuasion. The constitutional action of the mandamus aims to rule out possible illegal acts, making the probationary delay unfeasible. The case law of the TJPA was analyzed from the point of view of the recognition of valuation formalism and when possible procedural irregularities were found in the Writ of Mandamus. It was concluded on legal and philosophical foundations of dialogue for procedural advance in MS.

KEY WORDS: Access to justice. Writ of mandamus. Dialogic procedure. Persuasive rationality. Fundamental rights.

\section{Introdução}

O acesso à justiça é um tema sensível e objeto de preocupação e de amplo estudo, tendo suscitado a adoção de várias medidas legislativas e diversas posturas jurisdicionais ao longo do tempo.

Cumpre ressaltar que, para além das ondas renovatórias, há uma nova fase metodológica pautada pelo formalismo valorativo, na qual se considera o neoconstitucionalismo e se prestigiam os direitos fundamentais. 
Nessa esteira, apresenta-se aqui a proposta doutrinária atual quanto à concepção de interesse público fundada em direitos fundamentais.

Além disso, descreve-se o procedimento especial do mandado de segurança, cujo propósito consiste em afastar possíveis lesões (ou ameaças) a direitos decorrentes de ato ilegal ou abusivo de poder, salientando-se seus aspectos procedimentais, em especial a impossibilidade de dilação probatória.

Analisa-se o procedimento dialógico e sua potencialidade para garantir a melhor concretização dos direitos fundamentais e a expansão do papel do Judiciário, buscando-se responder ao seguinte questionamento: é possível uma solução dialógica para a melhor concretização de direitos fundamentais no remédio heroico, apesar da restrição de dilação probatória?

Objetiva-se demonstrar que a postura dialógica tem potencial para superar eventuais irregularidades processuais que impliquem extinções terminativas e assegurar a participação dos efetivos envolvidos, garantindo legitimidade democrática procedimental para fins de concretização dos direitos fundamentais. Além disso, a postura dialógica pode fornecer maiores subsídios ao juízo para melhor fundamentação arrazoada da sentença, dando legitimidade democrática substancial à decisão.

Recorre-se a dados extraídos de decisões do Tribunal de Justiça do Estado do Pará (TJPA) para ao final apontar uma conclusão objetiva acerca do cabimento do procedimento dialógico no mandado de segurança.

\section{2. $\mathrm{O}$ acesso à justiça a partir do diálogo e das necessidades humanas: características e implicações}

A argumentação racional é uma poderosa ferramenta de promoção da justiça. Com efeito, a promoção do debate e do diálogo amplo é imprescindível, pois, quanto mais diversos e diferentes forem os pontos de vista (pluralidade das razões a serem consideradas), maiores chances de se chegar a uma análise arrazoada, porque os 
argumentos nascem de perspectivas diferentes e o enfrentamento racional entre eles conduz a decisões melhores ${ }^{2}$.

Ademais, a falta de deliberação pública contribui para soluções ineficazes. A decisão judicial com a demonstração de argumentação racional pública popularmente aprovada é mais facilmente implementada, pois, até mesmo na democracia, que envolve uma elevada quantidade de pessoas, essas razões são levantadas para fins de convencimento das razões públicas apresentadas.

Em um contexto democrático, o diálogo e a interação pública constituem contribuições fundamentais, sendo necessário avaliar os argumentos contrários que viabilizem uma argumentação racional pública - fundamento para o engajamento aberto na busca da justiça. Deve-se considerar também a necessidade de aceitar a pluralidade de razões que podem caber sensatamente num exercício de avaliação ${ }^{3}$.

Com base na mesma lógica argumentativa, no caso de um mandado de segurança, que é matéria de interesse público, os sujeitos envolvidos podem e devem dialogar e avaliar os argumentos contrários que viabilizem uma argumentação racional pública com garantia dos direitos fundamentais na busca da justiça. Da mesma forma, deve-se considerar também a necessidade de aceitar a pluralidade de razões que podem caber sensatamente num exercício de avaliação dos direitos tuteláveis por via de mandado de segurança.

Noutra esteira, cumpre destacar a importância da pacificação e da educação social para viabilizar o plano de vida humano, com o atendimento das necessidades humanas. Eventuais "problemas" devem ser solucionados por meio de uma discussão que leve à assunção de um forte compromisso, inclusive pelo Judiciário, que precisa assegurar tempo, atenção e engajamento no desempenho do seu ofício ${ }^{4}$.

A propósito, o atendimento das necessidades humanas pode ser feito pelo Estado. A preocupação com a concretização dos direitos sociais para atender às

\footnotetext{
${ }^{2}$ SEN, Amartya. A ideia de justiça. Tradução de Denise Bottmann e Ricardo Doninelli Mendes. São Paulo: Companhia das Letras, 2011, p. 357-382.

${ }^{3}$ SEN, Amartya. A ideia de justiça. Tradução de Denise Bottmann e Ricardo Doninelli Mendes. São Paulo: Companhia das Letras, 2011, p. 423-431.

${ }^{4}$ DOYAL, Len; GOUGH, Ian. Una teoría de las necesidades humanas. Barcelona: Icaria, 1994, p. 263.
} 
necessidades humanas é própria de uma concepção social, em que se busca alcançar o bem-estar de cada um ${ }^{5}$.

A concretização e a exequibilidade dos direitos fundamentais - entre os quais os sociais e, consequentemente, o acesso à justiça - dependem de um sistema de integração e de cooperação entre os órgãos que visam o interesse coletivo, que defendem o critério material de justiça. Para cumprirem seu dever jurídico de atendimento dos interesses coletivos, não se podem criar óbices à concretização dos direitos fundamentais por parte do Judiciário ${ }^{6}$.

Destaque-se que o objetivo do direito é a justiça, não é a eficiência. $O$ conceito de justiça abrange um conjunto de valores mais ricos e mais profundos do que a simples eficiência, embora deva incluir algumas necessárias considerações sobre resultados eficientes. Por isso, o direito deve ser concebido como justiça, ainda que se reconheça que parte da justiça tenha relação com resultados eficientes ${ }^{7}$.

Aliás, a justiça do procedimento é fundamental para que se assegure o resultado correto. As questões de fundo do procedimento devem ser justas para que o procedimento também o seja. A desobediência à equidade ou à justiça no procedimento ensejará, consequentemente, um resultado injusto ${ }^{8}$.

O Judiciário deve assegurar a proteção jurídica efetiva em relação ao direito a procedimento, caso o direito não seja fruível ou exercitável por ausência de normas procedimentais. Por outras palavras, devem ser garantidos os direitos a procedimentos como direitos a ações estatais positivas de qualquer dos poderes estatais, legislativo, judicial, ministerial, administrativo, etc. Assim, a atividade jurisdicional, que consiste numa das funções estatais, deve interpretar e aplicar concretamente normas procedimentais (além de viabilizá-las, caso não existam), que consistem em direitos essenciais a uma proteção jurídica efetiva. Espera-se, em especial, que o resultado do procedimento proteja

\footnotetext{
5 SILVA, Sandoval Alves da. O Ministério Público e a concretização dos direitos humanos. Salvador: Juspodivm, 2016, p. 59 e p. 63.

6 SILVA, Sandoval Alves da. Direitos sociais: leis orçamentárias como instrumento de implementação. Curitiba: Juruá, 2007, p. 203-204.

${ }^{7}$ FISS, Owen. Modelos de adjudicação. Caderno de Direito GV, São Paulo, v. 1, n. 8, nov. 2005 , p. 42.

${ }^{8}$ RAWLS, 1971, p. 86 apud ANDRADE, Igor Ascarelli Castro de. Constituição e desigualdade em John Rawls. Belo Horizonte: Editora D’Plácido, 2018, p. 68-72.
} 
efetivamente os direitos materiais dos interessados e titulares de direitos fundamentais submetidos à discussão 9 .

No atual Estado Democrático de Direito, o prestígio conferido à justiça material, aliado ao desapego exagerado à forma como superação de uma das barreiras à onda renovatória do acesso à justiça, fundamentam uma atuação jurisdicional que se preocupa com a justiça da decisão, o que exige mecanismos procedimentais que tornem os direitos exequíveis. O acesso à justiça é um direito social, cabendo ao Judiciário tornar esse direito exequível, sendo "necessária uma concepção processual de justiça social no acesso à justiça, pois de nada adianta garantir materialmente um direito se processualmente não se garante o acesso à ordem jurídica justa" ${ }^{10}$.

A propósito, registre-se a necessidade de expansão do Judiciário, observadas determinadas limitações. Cabe ainda lembrar que democracia é sinônimo de participação, a qual é constatada, inclusive, no direito atribuído às partes de serem ouvidas igualmente, bem como em direitos e liberdades fundamentais. Conclui-se que "justamente no respeito a essas regras fundamentais está a melhor garantia da legitimidade democrática da função judiciária"11.

Frise-se a possível adaptação de regras técnicas do processo pelos tribunais, além de que o sentimento de participação pelo povo é essencialmente democrático. Nas demandas judiciais, cabe às partes iniciar e delimitar o conteúdo da decisão judicial, além de terem o direito fundamental de serem ouvidas. Conclui-se que o processo judicial pode ser considerado como o mais participativo de todos os processos da atividade política e que a democracia não pode ser interpretada unicamente como a ideia da maioria, requer sobretudo participação. Logo, o Judiciário pode dar uma ampla contribuição à democracia, na medida em que impede caprichos momentâneos, devendo ser suficientemente ativo, dinâmico e criativo, sem prejuízo da preservação do sistema de checks and balances $^{12}$.

\footnotetext{
${ }^{9}$ ALEXY, Robert. Teoria dos direitos fundamentais. São Paulo: Malheiros, 2008, p. 488.

10 SILVA, Sandoval Alves da. O (in)acesso à justiça social com a demolidora reforma trabalhista. In: MIESSA, Élisson; CORREIA, Henrique. (Org.). A reforma trabalhista e seus impactos. Salvador: Juspodivm, 2017. v. 1, p. 1085.

11 CAPPELLETTI, Mauro. Juízes legisladores? Tradução de Carlos Alberto Alvaro de Oliveira. Porto Alegre: Sergio Antonio Fabris, 1993, p. 80.

12 CAPPELLETTI, Mauro. Juízes legisladores? Tradução de Carlos Alberto Alvaro de Oliveira. Porto Alegre: Sergio Antonio Fabris, 1993, p. 100, p. 102 e p. 106.
} 
Em acréscimo, cumpre esclarecer a nova abordagem e o refinamento conceitual de "interesse público", que remete notadamente à implementação da dignidade da pessoa humana, com os direitos fundamentais e sociais elevados a protagonistas na interpretação do ordenamento jurídico-administrativo. Nessa concepção, "interesse público" aproxima-se de "interesses gerais". Por outro lado, os interesses possuem uma perspectiva dinâmica, com foco nos propósitos do Estado, além de teem ligação com a satisfação das necessidades sociais. Conclui-se que o instituto "interesse público" afirma os direitos fundamentais, em uma visão constitucional. Destaca-se o elemento conceitual material de margem positiva, no sentido de que o interesse público está ligado aos objetivos estatais e aos direitos fundamentais, observadas as necessidades humanas ${ }^{13}$.

Com efeito, é possível escrever o processo de acordo com as necessidades humanas, a teoria da justiça e a concepção de conflito e sua gestão.

Conforme exposto acima, fica demonstrado que, na onda renovatória de superação de irregularidades, o acesso à justiça é necessário, bem como sua concretização como direito social, inclusive pelo Estado-Juiz. Confirma-se ainda a necessária observância do acesso à justiça tendo em vista a necessidade humana intermediária, além da necessária adoção pelo Poder Público (inclusive, pelo Judiciário) de procedimentos de natureza participativa e dialógica, como instrumentos democráticos estritamente relacionados à ideia de justiça. Finalmente, registra-se a nova visão do atendimento do interesse público, agora ligado à realização dos direitos fundamentais.

\section{O procedimento especial do mandado de segurança: o direito líquido e certo e a impossibilidade de dilação probatória}

O procedimento especial do mandado de segurança é disciplinado pela Lei n. $^{\circ}$ 12.016/2009 - a chamada Lei do Mandado de Segurança (LMS) -, que prevê, em seu artigo $1{ }^{\text {o14 }}$, a sua concessão para a proteção de direito líquido e certo.

\footnotetext{
${ }^{13}$ HEINEN, Juliano. Interesse público: premissas teórico-dogmáticas e proposta de fixação de cânones interpretativos. Salvador: Juspodivm, 2018, p. 52, p. 72 , p. 94 e p. 96.

14 "Conceder-se-á mandado de segurança para proteger direito líquido e certo, não amparado por habeas corpus ou habeas data, sempre que, ilegalmente ou com abuso de poder, qualquer pessoa física ou jurídica sofrer violação ou houver justo receio de sofrê-la por parte de autoridade, seja de que categoria for e sejam quais forem as funções que exerça" (grifo nosso)
} 
Há discussão doutrinária quanto à natureza jurídica do direito líquido e certo no mandado de segurança: questiona-se se consiste em condição da ação, pressuposto processual ou mérito ${ }^{15}$.

A relevância dessa questão é cristalina, como se deduz do disposto na Súmula n. 304 do Supremo Tribunal Federal (STF): "Decisão denegatória de mandado de segurança, não fazendo coisa julgada contra o impetrante, não impede o uso da ação própria”.

Diante disso, caso se aprecie o mérito do pedido do Mandado de Segurança, há coisa julgada material e impedimento de reapreciação da controvérsia em ação ordinária. Caso o pedido seja apreciado por insuficiência de provas o mandamus restará infrutífero e extinto sem resolução de mérito, sem implicar em coisa julgada material; abrindo-se a possibilidade de ajuizamento de ação ordinária ${ }^{16}$.

Quanto a direito líquido e certo, trata-se de evolução da expressão "direito certo e incontestável", estando ligado ao amadurecimento dos fatos nele discutidos e não à complexidade. Consiste em fato certo, comprovável de plano e que não depende de maior instrução probatória ${ }^{17}$.

Nessa esteira, frise-se o entendimento jurisprudencial consolidado no Superior Tribunal de Justiça (STJ) ${ }^{18}$ no sentido de que no mandado de segurança o impetrante deve fazer prova indiscutível, completa e transparente do seu direito líquido e certo, sendo a dilação probatória incompatível com a natureza da ação mandamental ${ }^{19}$.

No mesmo sentido, o STF entende que cabe ao impetrante demonstrar, já com a petição inicial, em que consiste a ilegalidade ou a abusividade que pretende ver

\footnotetext{
${ }^{15}$ ARAÚJO, José Henrique Mouta. Mandado de segurança. 6. ed. Salvador: Juspodivm, 2017, p. 50.

${ }^{16}$ ARAÚJO, José Henrique Mouta. Mandado de segurança. 6. ed. Salvador: Juspodivm, 2017, p. 50-51.

${ }^{17}$ ARAÚJO, José Henrique Mouta. Mandado de segurança. 6. ed. Salvador: Juspodivm, 2017, p. 29-31.

18 "Mandado de segurança. Prova do direito líquido e certo. Por sua natureza, nas ações de mandado de segurança, com a inicial deve o impetrante fazer prova indiscutível, completa e transparente de seu direito líquido e certo. Não é possível trabalhar à base de presunções. Recurso conhecido mas improvido (STJ (2. Turma). Recurso Ordinário em Mandado de Segurança n. ${ }^{\circ}$ 929-SE-Reg. 91.0005573-5. Relator: Min. José de Jesus Filho. Data de julgamento: 20/05/1991. Publicação: DJU 24/06/1991). "O mandado de segurança é ação constitucionalizada instituída para proteger direito líquido e certo, sempre que alguém sofrer violação ou houver justo receio de sofrê-la por ilegalidade ou abuso de poder, exigindo-se prova pré-constituída como condição essencial à verificação da pretensa ilegalidade, sendo a dilação probatória incompatível com a natureza da ação mandamental. Precedentes [...]" (STJ (5. Turma). Embargos de declaração no agravo regimental no ROMS 12781. Processo: 200001432818/GO. Data de julgamento: 05/11/2002. Publicação: DJ 02/12/2002, p. 325).

${ }^{19}$ ARAÚJO, José Henrique Mouta. Mandado de segurança. 6. ed. Salvador: Juspodivm, 2017, p. 32.
} 
expungida do ordenamento jurídico, não havendo espaço para que demonstre sua ocorrência no decorrer do procedimento ${ }^{20}$.

Igualmente, a jurisprudência majoritária e mais atualizada do TJPA defende a impossibilidade de realização de instrução probatória $^{21}$ e a consequente ausência de êxito no remédio heroico quando envolver controvérsia quanto a ato administrativo que goza de presunção de veracidade e legitimidade referente à realização de perícia, se juntado laudo particular de controversa inaptidão física do candidato ${ }^{22}$. O mesmo ocorre em casos de controvérsia sobre a altura mínima exigida em edital, que também exigiria perícia para

20 “[...] assim me manifestei a respeito das consequências geradas pelo deficiente aparelhamento da inicial do mandado de segurança: A insuficiência do lastro probatório acarreta o insucesso da impetração, presentes as particularidades da ação mandamental, em que, como é cediço, se exige demonstração de direito líquido e certo. Sobre o tema, Cássio Scarpinella Bueno (Mandado de Segurança: Comentários às Leis n. 1.533/51, 4.348/64 e 5021/66. São Paulo: Saraiva, $5^{\text {a }}$ edição, 2009, pp. 15-6) destaca: [...] Por direito líquido e certo deve ser entendido aquele direito cuja existência e delimitação são claras e passíveis de demonstração documental. Hely Lopes Meirelles tem passagem clássica em que afirma que melhor seria a fórmula constitucional (e legal) ter-se referido à necessidade de o fato que dá supedâneo à impetração ser líquido e certo e não o direito em si mesmo. Para ele, o direito líquido e certo é um conceito impróprio e mal-expresso - alusivo à precisão e comprovação do direito quando deveria aludir à precisão e comprovação dos fatos e situações que ensejam o exercício desse direito (Hely Lopes Meirelles, Mandado de segurança, ação popular, ação civil pública, mandado de injunção, habeas data, ação direta de inconstitucionalidade e ação declaratória de constitucionalidade, p. 36). Essa interpretação da expressão direito líquido e certo relaciona-se intimamente ao procedimento célere, ágil, expedido e especial do mandado de segurança, em que, por inspiração direta do habeas corpus, não é admitida qualquer dilação probatória. É dizer: o impetrante deverá demonstrar, já com a petição inicial, no que consiste a ilegalidade ou a abusividade que pretende ver expungida do ordenamento jurídico, não havendo espaço para que demonstre sua ocorrência no decorrer do procedimento. A jurisprudência desta Corte é firme no sentido de que o mandado de segurança deve ser impetrado com todas as provas necessárias à demonstração das circunstâncias de fato embasadoras da controvérsia. Embora não seja vedada a determinação para emenda da inicial de mandado de segurança nos termos do art. 284 do CPC, aplicado subsidiariamente em algumas hipóteses (v.g., exemplificativamente, o MS 24.812 AgR/DF, Pleno, Ministro Marco Aurélio, DJ de 18.3.2005), não se viabiliza a emenda da inicial no caso de omissões de tal magnitude que impeçam a própria constatação do direito líquido e certo. [...]" (STF. MS 32920 DF. Relatora: Min. Rosa Weber. Data de julgamento: 05/05/2014. Publicação: DJe-099 DIVULG 23/05/2014 PUBLIC 26/05/2014).

21 Ocorre que o procedimento dialógico consiste num dos elementos da democracia que permite a racionalidade persuasiva pública, característica que deveria ser observada em todos os procedimentos no atual Estado Democrático de Direito, inclusive nos submetidos à jurisdição. No mandado de segurança, há uma restrição ainda maior no que se refere à instrução probatória, a qual, contudo, não pode inviabilizar o exercício do diálogo racional.

22 "Poder Judiciário. Tribunal de Justiça do Estado do Pará. Processo n. o 0005366-63.2017.814.0000. Órgão julgador: 2. ${ }^{a}$ Turma de Direito Público. Recurso: agravo de instrumento. Comarca: Belém (2. ${ }^{\mathrm{a}}$ Vara de Fazenda Pública). Agravante: Handersonn Chrystyann Torres Nogueira. Advogado: Sebastião Halim Soares Habr - OAB 3343 e José Nogueira - OAB 5850-E. Agravado: Presidente da Banca da Fundação de Amparo e Desenvolvimento da Pesquisa - Fadesp. Endereço: rua Augusto Correia, s/n - Cidade Universitária Professor José da Silveira Netto/UFPA, Guamá, CEP: 66075-110. Belém-Pará. Relator: Des. Luiz Gonzaga da Costa Neto. Decisão monocrática. Agravo de instrumento. pedido de efeito suspensivo. Laudo da junta médica oficial. Exame particular. Divergência. Necessidade de dilação probatória. Presunção de legalidade e veracidade dos atos administrativos. Prevalência do laudo oficial. Não provimento do recurso" (TJPA (2. Turma de Direito Público). 2019.02334038-35, não informado. Relator: Luiz Gonzaga da Costa Neto. Data de julgamento: 11/06/2019. Publicação: 11/06/2019). 
viabilizar a adequada instrução probatória ${ }^{23}$, ou quando é necessária a comprovação de suposta ilegalidade decorrente de cerceamento de defesa em ato que anulou concurso público por meio de decreto ${ }^{24}$, ou, ainda, quando constatada a impossibilidade de concessão de adicional de periculosidade sem o respectivo laudo pericial ${ }^{25}$.

Noutra esteira, o TJPA tem decidido pela extinção terminativa do mandamus, seja por inaplicabilidade da teoria da encampação na ausência de vínculo hierárquico ${ }^{26}$, seja por impossibilidade de correção do polo passivo de ofício pelo Judiciário ${ }^{27}$.

Ocorre que já existe entendimento doutrinário e jurisprudencial admitindo a flexibilidade do remédio heroico em relação à possível substituição da autoridade coatora e do impetrante. Isso porque os Enunciados n..$^{\circ} 42$ e n. 511 do Fórum Permanente de Processualistas Civis (FPPC), bem como o Enunciado n. ${ }^{\circ} 123$ do Conselho de Justiça Federal (CJF) admitem a correção da autoridade coatora, a partir da aplicação dos artigos

\footnotetext{
23 "Poder Judiciário. Tribunal de Justiça do Estado do Pará. Processo n. ${ }^{\circ} 00072624420178140000$. Órgão julgador: 2. ${ }^{a}$ Turma de Direito Público. Recurso: agravo de instrumento. Comarca: Belém (3. ${ }^{a}$ Vara da Fazenda). Agravante: Estado do Pará. Procurador de justiça: Gustavo Lynch - OAB/PA n. ${ }^{\circ}$ 10.261. Agravado: Rafael Henrique Lima Sobrinho. Advogado: Marco Antonio Gomes de Carvalho - OAB/PA n. ${ }^{\circ}$ 7932. Relator: Des. Luiz Gonzaga da Costa Neto. Decisão monocrática. Agravo de instrumento. Mandado de segurança. Ingresso na Polícia Militar. Concurso público. Altura mínima exigida. Requisito previsto no edital e em lei específica. Lei Estadual n. ${ }^{\circ} 6.626 / 2004$. Estatura mínima prevista em edital e em lei estadual não alcançada. Recurso conhecido e provido" ( TJPA (2. Turma de Direito Público). 2019.02306918-12, não informado. Relator: Luiz Gonzaga da Costa Neto. Data de julgamento: 10/06/2019. Publicação: 10/06/2019). 24 “Poder Judiciário. Tribunal de Justiça do Estado do Pará. 2. ${ }^{a}$ Turma de Direito Público - Apelação Cível n. ${ }^{\circ}$ 0000481-53.2013.8.14.0062. Relatora: Desembargadora Luzia Nadja Guimarães Nascimento. Apelante: Rafael Ribeiro de Oliveira. Advogada: Ivonete Orio (OAB/PA 8.329). Apelado: Município de Tucumã. Procurador do Município: Renato André Barbosa dos Santos (OAB/PA 12.682). Procurador de justiça: Raimundo de Mendonça Ribeiro Alves. Ementa. Apelação cível. Concurso público. Município de Tucumã. Suspensão e anulação do certame. Necessidade de ampla dilação probatória para averiguação dos processos administrativos e judiciais que embasaram os decretos anulatórios. Providência incabível na via mandamental. Recurso conhecido e não provido. Decisão monocrática" (TJPA (2. Turma de Direito Público). 2019.01439098-89, não informado. Relatora: Luzia Nadja Guimaraes Nascimento. Data de julgamento: 16/04/2019. Publicação: 16/04/2019).

${ }^{25}$ No mesmo sentido: TJPA (2. Turma de Direito Público). Apelação Cível n. ${ }^{\circ}$ 2019.01269417-76, não informado. Relatora: Luzia Nadja Guimaraes Nascimento. Data de julgamento: 04/04/2019. Publicação: 04/04/2019.

26 “Administrativo e constitucional. Apelação cível. Mandado de segurança - afastamento do cargo de prefeito. Ato coator omissivo. Ausência de notificação para apresentação de defesa. Comissão processante. Legitimidade passiva. Presidente da comissão de investigação. Extinção do mandamus sem resolução do mérito. Ilegitimidade passiva. Sentença mantida" (TJPA (1. Turma de Direito Público). 2018.01233731-95, 188.069. Relatora: Celia Regina de Lima Pinheiro. Data de julgamento: 26/03/2018. Publicação: 06/04/2018).

27 "Agravo de instrumento - mandado de segurança. Servidor público. Errônea indicação da autoridade coatora. Ilegitimidade passiva. Art. 485, VI, do Código de Processo Civil. Necessária extinção do processo originário sem resolução de mérito" (TJPA (2. Turma de Direito Público). 2017.03496871-45, 179.504. Relatora: Nadja Nara Cobra Meda. Data de julgamento: 17/08/2017. Publicação: 18/08/2017).
} 
338 e 339 do Código de Processo Civil (CPC) ao procedimento especial do mandado de segurança ${ }^{28}$.

No mesmo sentido, o STJ admitiu a correção da autoridade coatora, com a respectiva emenda da inicial, dada a impossibilidade de se exigir do impetrante o conhecimento da complexa estrutura da administração pública, desde que não haja alteração da competência judiciária, e se as duas autoridades fizerem parte da mesma pessoa jurídica de direito público ${ }^{29}$.

Aliás, a possível substituição da autoridade coatora é recomendável, inclusive para melhor esclarecimento efetivo da questão em debate, evitando-se eventual eficácia preclusiva indevida em prestação insuficiente ou inadequada de informações, garantindo-se o adequado contraditório participativo por meio da abertura de prazo ao impetrante para indicação da autoridade correta $^{30}$ e a isonomia processual, assegurando-se a dialeticidade necessária a uma decisão judicial leal ${ }^{31}$.

Igualmente, não se descarta a possível substituição do impetrante nas ações coletivas, entre as quais se enquadra o mandado de segurança coletivo (MSC), por analogia ao disposto no artigo $5^{\circ}, \S 3 .^{\circ}$, da Lei de Ação Civil Pública (LACP), intimando-se o legitimado ativo para eventual manifestação no prosseguimento do feito ${ }^{32}$.

Nesse sentido, de acordo com o princípio do microssistema da tutela coletiva, haverá aplicação integrada das leis para a tutela coletiva. Assim, eventual lacuna legislativa de processo coletivo deve ser suprida pelo magistrado dentro desse próprio microssistema

\footnotetext{
${ }^{28}$ Enunciado FPPC n. ${ }^{\circ}$ 42: “(art. 339) O dispositivo aplica-se mesmo a procedimentos especiais que não admitem intervenção de terceiros, bem como aos juizados especiais cíveis, pois se trata de mecanismo saneador, que excepciona a estabilização do processo. (Grupo: Litisconsórcio, Intervenção de Terceiros e Resposta do Réu)". Enunciado FPPC n. ${ }^{\circ}$ 511: “(art. 338, caput; art. 339; Lei n. 12.016/2009) - A técnica processual prevista nos arts. 338 e 339 pode ser usada, no que couber, para possibilitar a correção da autoridade coatora, bem como da pessoa jurídica, no processo de mandado de segurança. (Grupo: Impacto do novo CPC e os processos da Fazenda Pública)". Enunciado CJF n. ${ }^{\circ}$ 123: "Aplica-se o art. 339 do CPC à autoridade coatora indicada na inicial do Mandado de segurança e à pessoa jurídica que compõe o polo passivo".

${ }^{29}$ STJ (2. Turma). AgRg no AREsp: 368159 PE 2013/0210240-3. Relator: Min. Humberto Martins. Data de julgamento: 01/10/2013. Publicação: DJe 09/10/2013; STJ (1. Turma). RMS: 17889 RS 2004/0021202-7. Relator: Min. Luiz Fux. Data de julgamento: 07/12/2004. Publicação: DJ 28/02/2005.

${ }^{30}$ SOKAL, Guilherme Jales. A teoria da encampação no mandado de segurança. Trabalho apresentado no XXXIX Congresso Nacional de Procuradores do Estado e do Distrito Federal. Porto de Galinhas, 2013, p. 23 e p. 29

${ }^{31}$ FARIA, Marcio Carvalho. A lealdade processual na prestação jurisdicional: em busca de um modelo de juiz leal. São Paulo: Revista dos Tribunais, 2017, p. 412.

32 ARAÚJO, Rodrigo Mendes de. A representação adequada nas ações coletivas. Salvador: Juspodium, 2013, p. 242.
} 
de tutela coletiva, sendo a legislação do processo individual usada somente de maneira residual; consistindo numa aplicação da teoria do diálogo das fontes ${ }^{33}$.

Ainda quanto à possível substituição do impetrante, há lição doutrinária e entendimento jurisprudencial admitindo sucessão processual quando se tratar de herdeiros ou de pessoa jurídica ${ }^{34}$.

Além disso, cumpre destacar a atual fase metodológica do formalismo valorativo. Houve uma evolução em relação às fases processuais anteriores, em especial, em relação ao processualismo, no qual se priorizavam a forma e a rigidez excessiva em detrimento do direito material.

O formalismo valorativo consiste num desdobramento do neoconstitucionalismo. Por sua vez, o neoconstitucionalismo se apresenta como aspecto filosófico e teórico para distinção entre regras e princípios, dando-lhes força normativa com o escopo de ampliar a efetividade da Constituição, prestigiando-se a força normativa dos princípios $^{35}$.

Nesse contexto, o formalismo valorativo busca a realização da justiça material da decisão e a pacificação social, prestigiando a boa-fé e a lealdade processual, impondo cooperação recíproca entre juiz e partes (ou demais sujeitos), em detrimento de um formalismo excessivo que poderia, inclusive, inibir o desempenho dos direitos fundamentais do jurisdicionado ${ }^{36}$.

Frise-se que o formalismo valorativo é reconhecido pelo TJPA, que o menciona expressamente em diversos julgados a fim de evitar formalismos exacerbados, em especial na tutela ou em demandas processuais sobre os direitos do consumidor (nos casos de sociedade de propósito específico e para garantir a tutela do hipossuficiente) ${ }^{37}$. O

\footnotetext{
${ }^{33}$ DIDIER JR., Fredie; ZANETI JR., Hermes. Curso de Direito Processual Civil: processo coletivo. 12. ed. São Paulo: Juspodivm, 2017.

${ }^{34}$ ARAÚJO, José Henrique Mouta. Mandado de segurança. 6. ed. Salvador: Juspodivm, 2017, p. 185-186.

${ }^{35}$ CAMBI, Eduardo. Neoconstitucionalismo e neoprocessualismo. Revista do Programa de Pós-Graduação em Direito da Universidade Federal da Bahia, Salvador, n. 17, 2008.2, p. 97, p. 98 e p. 105.

36 OLIVEIRA, Carlos Alberto Alvaro de. O formalismo-valorativo no confronto com o formalismo excessivo. Revista da Faculdade de Direito da UFRGS, Porto Alegre, n. 26, 2006, p. 64, p. 79-80 e p. 85.

37 “....] Observa-se que ambas as empresas possuem os mesmos administradores e representantes, endereço, bem como os mesmos patronos, o que indica o vínculo jurídico e econômico existente entre as agravantes. $\mathrm{O}$ Código Consumerista, em seu art. $3 .^{\circ}$, estabelece que fornecedor é todo aquele que participa da cadeia de produção ou prestação de serviço, ainda que, do ponto de vista formal contratual, possa eventualmente não ter contraído obrigações diretamente perante o consumidor. Certo que fornecedor não é apenas aquele que contrata diretamente com o consumidor, mas também todos os que integram a cadeia de fornecimento. Com
} 
TJPA também menciona o formalismo valorativo na aferição de tempestividade de recurso protocolado antes do termo inicial, prestigiando a boa-fé e a celeridade processual ${ }^{38}$, e na inadmissibilidade de apelação que questionou a ausência do nome do genitor na sentença homologatória de acordo de alimentos celebrado pela Defensoria Pública que já consistia em título executivo, considerando que nem sequer era necessária a homologação ${ }^{39}$.

efeito, o que vem se notando, hodiernamente, é que certas empresas, vêm se comportando a todo o tempo como autênticas parceiras comerciais, o que atrai a legitimidade e responsabilidade de ambas, atentando-se, sobretudo, para a teoria da aparência. [...] § 3. ${ }^{\circ}$ Toda e qualquer incorporação, independentemente da forma por que seja constituída, terá um ou mais incorporadores solidariamente responsáveis, ainda que em fase subordinada a período de carência, referido no art. 34. A formação dessas sociedades de propósito específico (SPE's) revelam-se, muitas das vezes, a meu sentir, manobra para reduzir e/ou dificultar eventual ação dos consumidores vindicando direitos. Isso é notório quando se constata a realização de outro empreendimento por ambas, criando-se a SPE com capital social reduzido, obstacularizando o acesso pleno dos adquirentes das unidades. Destarte, o reconhecimento da responsabilidade solidária importa em relevante válvula de vedação de possíveis subterfúgios concebidos para, em regra, ludibriar o consumidor mediante a proliferação de distintas personalidades jurídicas, não raro estabelecidas com a finalidade exclusiva de frustrar os direitos dos adquirentes, em especial à reparação de danos que lhes venham a ser causados. Não cabe mais, hoje, o formalismo exacerbado em detrimento do formalismo valorativo. Portanto, a ficção jurídica da sociedade de propósito específico não deve ser interpretada de maneira absoluta na realidade complexa em que as duas personalidades jurídicas das empresas, como no caso das agravantes, se entrelaçam e se confundem. Nesse raciocínio, é a jurisprudência do TJ/RJ: [...] Destaco que o objetivo do legislador com a instituição do Código de Defesa do Consumidor não foi privilegiar o consumidor, mas tão somente igualá-lo ao fornecedor de bens ou prestador de serviços, portanto, é justamente na busca deste equilíbrio entre as partes envolvidas na relação de consumo, é que foi instituído o mecanismo da inversão do ônus da prova, quando presente a verossimilhança das alegações e hipossuficiência do consumidor. A verossimilhança consiste na coerência, a aparência de verdade quanto às alegações de descumprimento contratual no que se refere ao atraso na entrega do imóvel. Já a hipossuficiência seria a disparidade de conhecimento técnico existente entre as partes, ao passo essa discrepância é relevante quando impede, dificulta ou impossibilita a apresentação de elementos probatórios acerca de fatos controvertidos pela parte vulnerável, no caso, os compradores [...]" (TJPA (2. Turma de Direito Privado). 2015.01855940-89, não informado. Relatora: Maria de Nazare Saavedra Guimaraes. Data de julgamento: 29/05/2015. Publicação: 29/05/2015).

38 Apelação Cível. Aplicação das normas processuais. Ação revisional de alimentos. Incomprovada alteração da capacidade financeira do alimentante. Mantido o valor dos alimentos. Sentença confirmada. Recurso conhecido e improvido à unanimidade. 1. Ante o disposto no art. 14 , do CPC/2015, tem-se que a norma processual não retroagirá, de maneira que devem ser respeitados os atos processuais e as situações jurídicas consolidadas sob a vigência da lei revogada. Desse modo, hão de ser aplicados os comandos insertos no CPC/1973, vigente por ocasião da publicação e da intimação da decisão recorrida. 2. Inexistindo prova a amparar a alegada mudança na situação financeira do alimentante, tampouco que houve diminuição das necessidades da parte credora, deve seguir inalterada a pensão alimentícia revisanda. 3. Recurso de Apelação conhecido e DESPROVIDO” (TJPA (2. Câmara Cível Isolda). 2016.03816863-30, 164.869. Relator: Roberto Goncalves de Moura. Data de julgamento: 05/09/2016. Publicação: 25/11/2016).

39 "[...] Compulsando os autos, verifico que, no acordo em que se buscou homologação, constam os elementos reclamados pelo apelante: nome das partes e percentual da pensão. Assim, fere o princípio da efetividade da tutela jurisdicional além de configurar formalismo processual exacerbado a exigência de que a mera sentença homologatória do acordo realizado perante a Defensoria Pública fizesse referência expressa aos elementos citados acima. $\mathrm{O}$ formalismo processual não pode ser interpretado de maneira desvinculada de sua finalidade, que é a garantia de um processo justo, célere, prático e desenvolvido em paridade de armas. Apoiando-se na autoridade de Mauro Cappelletti, Carlos Alberto Álvaro de Oliveira afirma que só é lícito pensar no conceito de formalismo 'na medida em que se prestar para a organização de um processo justo e servir para alcançar as finalidades últimas do processo em tempo razoável e, principalmente, colaborar para a 
Ademais, também já existe manifestação do TJPA admitindo a juntada posterior de documentos, com fundamento no artigo 321 do CPC/2015. É o que se depreende do despacho judicial de 2 de maio de 2019 em um mandado de segurança coletivo (MSC) $)^{40}$, em que o impetrante foi instado a apresentar prova documental posterior (autorização de descontos) que não constava da inicial, o que ocasionou um pedido de desistência protocolado em 28 de maio de 2019.

Contudo, o TJPA tem decidido majoritariamente pela extinção terminativa do feito, conforme conclusões da $1 .^{a}$ e da $2 .^{a}$ Turma de Direito Público, da Seção de Direito Público e do Tribunal Pleno.

A 1. 'Turma de Direito Público concluiu pela extinção terminativa do processo, por exemplo, quando observada a indicação errônea do Presidente da Câmara Municipal de Rio Maria para concessão de reajuste de vencimentos de servidores públicos municipais; no caso, caberia ao Prefeito Municipal enviar Projeto de Lei, conforme artigo 61, § 1. ${ }^{\circ}$, II, 'a' da CRFB/1988. A mesma Turma concluiu pela extinção terminativa do processo na indicação errônea do Presidente da Câmara de Porto de Moz para apresentação de defesa,

justiça material da decisão'. ('O formalismo-valorativo no confronto com o formalismo excessivo', Revista de Processo 137, págs. 7 a 31, esp. pág. 13). Assim, o juiz não está autorizado a interpretar a lei processual de maneira a dificultar que se atinja uma solução para o processo se há, paralelamente, uma forma de interpretála de modo a se chegar a tal solução. Nesse diapasão, o próprio acordo celebrado perante a Defensoria Pública constitui título executivo, na forma do que estabelece o art. 585, II, do CPC: Art. 585. São títulos

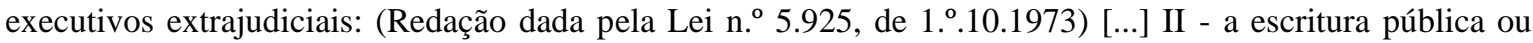
outro documento público assinado pelo devedor; o documento particular assinado pelo devedor e por duas testemunhas; o instrumento de transação referendado pelo Ministério Público, pela Defensoria Pública ou pelos advogados dos transatores; (Redação dada pela Lei n. ${ }^{\circ} 8.953$, de 13.12.1994). Por essa razão, sequer havia a necessidade de se ajuizar a presente ação para ser exequível o acordo em testilha, haja vista que, uma vez descumprido os termos do acordo, poder-se-á ajuizar a ação executiva imediatamente. [...] O escopo do processo executivo das ações de alimentos é dar efetividade à prestação jurisdicional, assegurando a célere quitação das prestações alimentícias, pelos meios mais eficazes, sejam ele os descontos em folha, a prisão civil, o rito da constrição patrimonial, dentre outros, impondo, inclusive às repartições públicas a obrigação de prestar informações necessárias ao processo. A interpretação sistêmica dos dispositivos que regem a matéria (artigos 16 a 20 da Lei n. ${ }^{\circ}$ 5.478/68 e 732 a 735 do CPC) não permite estabelecer distinção entre o acordo referendado pela Defensoria Pública, pelo Ministério Público ou pelos advogados das partes (art. 585, II, CPC) e a sentença judicial que fixam os alimentos. De mais disso, sentença meramente homologatória de acordo não possui conteúdo próprio, limitando-se apenas a referendar vontade das partes manifestada no acordo. ANTE O EXPOSTO, na esteira do parecer ministerial, NEGO SEGUIMENTO à presente APELAÇÃO CÍVEL, ante sua manifesta improcedência, tudo nos termos e limites da fundamentação lançada, que passa a integrar o presente dispositivo como se nele estivesse totalmente transcrita. P.R.I. Belém (PA), 21 de agosto de 2015. Dra . Ezilda Pastana Mutran. Relatora/juíza convocada” (TJPA (2. Câmara Cível Isolada). 2015.03075952-57, não informado. Relatora: Ezilda Pastana Mutran, juíza convocada. Data de julgamento: 24/08/2015. Publicação: 24/08/2015).

40 Mandado de Segurança Coletivo n. ${ }^{\circ}$ 0800179-86.2019.814.0124, proposto pelo Sindicato dos Trabalhadores em Saúde Pública do Estado do Pará contra o município de São Domingos do Araguaia, que tramitou na Vara Única daquele Município no Processo Judicial Eletrônico. 
por suposta ausência de notificação do Prefeito investigado, quando a legitimidade para tal seria do Presidente da Comissão Processante ${ }^{41}$.

Por sua vez, a 2. ${ }^{a}$ Turma de Direito Público concluiu pela extinção terminativa quando foi indicado como autoridade coatora o servidor responsável por meros atos operacionais sem poder de decisão de suspensão remuneratória, ou sem poder de decisão para concessão de benefício fiscal ${ }^{42}$.

Já a Seção de Direito Público manifestou-se pela extinção sem resolução do mérito em decorrência de indevida indicação de Secretário ou Governador que genericamente orientam os órgãos subordinados, cabendo o remédio contra aquela autoridade que tenha praticado o ato impugnado ou do qual emane a ordem para sua prática - o servidor da Administração Tributária, Coordenador da Coordenação Executiva Regional de Administração e Tributária (CERAT). No caso, buscou-se evitar o lançamento fiscal ou o auditor-fiscal competente para analisar o processo administrativo fiscal ${ }^{43}$.

\footnotetext{
41 "Processo civil e constitucional - Apelação - Mandado de segurança? Preliminar de ilegitimidade passiva da Presidente da Câmara Municipal de Rio Maria. Acolhida - Servidores Públicos da Câmara Municipal de Rio Maria. Lei específica sobre revisão geral anual de vencimentos. Iniciativa do Prefeito Municipal. Legitimidade passiva. Extinção do mandamus sem resolução do mérito. Art. 267, VI, do CPC/73 e art. 6. ${ }^{\circ}, \S$ 3. ${ }^{\circ}$, da Lei n. ${ }^{\circ}$ 12.016/2009” (TJPA (1. Turma de Direito Público). 2018.01599663-48, 189.261. Relatora: Celia Regina de Lima Pinheiro. Data de julgamento: 16/04/2018. Publicação: 03/05/2018). “Administrativo e constitucional. Apelação cível. Mandado de segurança - Afastamento do cargo de prefeito. Ato coator omissivo. Ausência de notificação para apresentação de defesa. Comissão Processante. Legitimidade passiva. Presidente da Comissão de Investigação. Extinção do mandamus sem resolução do mérito. Ilegitimidade passiva. Sentença mantida" (TJPA (1. Turma de Direito Público). 2018.01233731-95, 188.069. Relatora: Celia Regina de Lima Pinheiro. Data de julgamento: 26/03/2018. Publicação: 06/04/2018).

42 Agravo de instrumento - Mandado de segurança. Servidor público. Errônea indicação da autoridade coatora. Ilegitimidade passiva. Art. 485, VI, do Código de Processo Civil. Necessária extinção do processo originário sem resolução de mérito. 1. Autoridade coatora, no mandado de segurança, é aquela que pratica, ordena ou omite a prática do ato impugnado (Lei Federal n. ${ }^{\circ} 12.016 / 09$, art. $6 .^{\circ}, \S 3 .^{\circ}$ ), além de deter, na ordem hierárquica, poder de decisão, com competência para praticar atos administrativos decisórios. 2. A ilegitimidade passiva da autoridade coatora acarreta a extinção do feito, sem resolução do mérito, a teor do art. 485, inciso VI, do Código de Processo Civil, ante a impossibilidade de o Poder Judiciário corrigir de ofício o polo passivo do mandamus. 3. No caso em tela, a autoridade apontada como coatora na exordial, sr. Bruno Jorge Rodrigues Alcântara, tido como responsável em suspender a remuneração da impetrante, é responsável apenas por atividades meramente operacionais, não possuindo competência e tampouco poderes à prática de atos administrativos decisórios. Assim, descuidando-se a agravada de indicar corretamente a Autoridade Coatora, ônus que lhe incumbia, deve o feito ser extinto, sem julgamento do mérito. 4. Recurso conhecido e provido para conceder efeito translativo e extinguir a ação mandamental no juízo de piso" (TJPA (2. Turma de Direito Público). 2017.03496871-45, 179.504. Relatora: Nadja Nara Cobra Meda. Data de julgamento: 17/08/2017. Publicação: 18/08/2017). No mesmo sentido: TJPA (2. Turma de Direito Público). AI n. ${ }^{\circ}$ 2017.02931114-10, não informado. Relatora: Nadja Nara Cobra Meda. Data de julgamento: 25/07/2017. Publicação: 25/07/2017.

43 "Embargos de declaração em mandado de segurança. Ilegitimidade passiva da autoridade coatora. Reconhecido. Teoria da encampação. Inaplicabilidade. Recurso conhecido e provido" (TJPA (Seção de Direito Público). 2018.03167595-73, 194.025. Relatora: Nadja Nara Cobra Meda. Data de julgamento:
} 
O Tribunal Pleno concluiu pela extinção terminativa processual no mandamus em que se discutiu a nomeação de servidor aprovado em concurso público pelo Secretário Estadual, quando deveria figurar o Chefe do Executivo, ou quando se pleiteou acréscimo remuneratório ao Chefe do Executivo, quando a legitimidade caberia ao Secretário de Estado $^{44}$.

Ocorre que a exigência do procedimento especial quanto à proteção de direito líquido e certo (que não admite a dilação probatória) não deve implicar impedimento de correção dos sujeitos processuais da relação jurídico-material, visto que se trata não de dilação probatória, mas de técnica de saneamento dos polos processuais, em especial, pela aplicação dos artigos 338 e 339 do CPC/2015 que retirou a natureza de intervenção de terceiros da nomeação à autoria, inserindo-a como técnica de saneamento do polo passivo da demanda, ou, ainda, pela aplicabilidade de outros fundamentos legais (como os artigos $6^{\circ}, 139$, IX, 317 e 321 do CPC/2015 $5^{45}$ ) e/ou filosóficos, inclusive, quando importar em alteração de competência, conforme será demonstrado a seguir.

07/08/2018. Publicação: 08/08/2018). No mesmo sentido: TJPA (Seção de Direito Público). MS n. ${ }^{\circ}$ 2018.02004488-13, não informado. Relatora: Rosileide Maria da Costa Cunha. Data de julgamento: 21/05/2018. Publicação: 21/05/2018.

44 "Constitucional e administrativo. Mandado de segurança - Preliminar de ilegitimidade passiva do Governador do Estado. Acolhida - Militar da ativa. Pagamento de gratificação de risco de vida. Indicação errônea da autoridade coatora. Extinção sem resolução do mérito - Teoria da encampação. Não aplicação" (TJPA (Tribunal Pleno). 2018.02615776-31, 193.257. Relatora Celia Regina de Lima Pinheiro. Data de julgamento: 27/06/2018. Publicação: 06/07/2018). "Processo n. ${ }^{\circ}$ 0007162-26.2016.8140000. Órgão julgador: Tribunal Pleno. Mandado de segurança. Comarca de Belém. Impetrante: Tiago Messias Cardoso Batista. Advogado(a): Dra. Liane Benchimol de Matos Albano - defensora pública. Impetrado: Secretaria de Estado de Administração do Estado do Pará - Sra Alice Viana Soares e Comandante Geral do Corpo de Bombeiros Militar do Estado do Pará - CEL. QOBM Nahum Fernandes da Silva. Relatora: Desembargadora Célia Regina de Lima Pinheiro. Ementa: Processual civil. Mandado de segurança. Indicação incorreta da autoridade coatora. Modificação do polo passivo de ofício. Impossibilidade. Carência de ação. Processo extinto sem julgamento de mérito" (TJPA (Tribunal Pleno). 2016.02745673-87, não informado. Relatora: Celia Regina de Lima Pinheiro. Data de julgamento: 13/07/2016. Publicação: 13/07/2016).

45 Art. 6. " "Todos os sujeitos do processo devem cooperar entre si para que se obtenha, em tempo razoável, decisão de mérito justa e efetiva”. Art. 139: "O juiz dirigirá o processo conforme as disposições deste Código, incumbindo-lhe: [...] IX - determinar o suprimento de pressupostos processuais e o saneamento de outros vícios processuais". Art. 317: “Antes de proferir decisão sem resolução de mérito, o juiz deverá conceder à parte oportunidade para, se possível, corrigir o vício”. Art. 321: “O juiz, ao verificar que a petição inicial não preenche os requisitos dos arts. 319 e 320 ou que apresenta defeitos e irregularidades capazes de dificultar o julgamento de mérito, determinará que o autor, no prazo de 15 (quinze) dias, a emende ou a complete, indicando com precisão o que deve ser corrigido ou completado. Parágrafo único. Se o autor não cumprir a diligência, o juiz indeferirá a petição inicial". 
Dessa forma, viabiliza-se possível legitimidade democrática procedimental ${ }^{46}$ que assegura a participação dos efetivos envolvidos e com maior aptidão para o fornecimento das melhores razões, para evitar possíveis prejuízos decorrentes da extinção terminativa ou da encampação inadequada ${ }^{47}$.

Ademais, o exercício da racionalidade persuasiva e o necessário engajamento do Judiciário quanto às razões argumentativas plurais dos legítimos sujeitos processuais que tenham maior aptidão ao fornecimento das razões pertinentes são recomendáveis para que se assegure o efetivo compromisso e a lealdade judicial na apreciação das razões, e a legitimidade da decisão quanto ao seu conteúdo, conforme será exposto a seguir.

\section{O procedimento dialógico na concretização de direitos fundamentais e o papel do}

\section{Judiciário}

Para a adequada comunicação, determinadas condições devem ser respeitadas para que o argumento possa ocorrer em sua forma mais frutífera, racional e democrática. Assim, os participantes devem ter o melhor entendimento disponível sobre as questões técnicas levantadas pelo problema que estejam tentando resolver e a comunicação destinada a melhorar a compreensão técnica e prática deve ser a mais democrática possível, afastando-se restrições indevidas em sua direção, conteúdo e extensão ${ }^{48}$.

Deve-se buscar a solução das demandas para concretizar os direitos sociais, como o acesso à justiça, de forma dialógica e com fundamento na racionalidade persuasiva e na proteção dos direitos humanos ${ }^{49}$.

A respeito do modelo de juiz leal, exige-se do Judiciário, entre outros, o princípio da cooperação. O rigor excessivo do magistrado para com os formalismos processuais pode ser enumerado como "ferramenta desleal da atuação jurisdicional",

\footnotetext{
${ }^{46}$ BRANDÃO, Rodrigo. Supremacia judicial versus diálogos constitucionais: a quem cabe a última palavra sobre o sentido da Constituição? Rio de Janeiro: Lumen Juris, 2012, p. 270.

47 JESUS, Thiago Vasconcellos. O princípio da cooperação e contraditório no MS: a aplicação dos arts. 338 e 339 do CPC/15 no procedimento especial do MS e possíveis benefícios processuais. Trabalho apresentado no XLIV Congresso Nacional de Procuradores do Estado e do Distrito Federal. Salvador, 2018, p. 14.

${ }^{48}$ HABERMAS, 1971, p. 176 apud DOYAL, Len; GOUGH, Ian. Una teoría de las necesidades humanas. Barcelona: Icaria, 1994, p. 163-165.

${ }^{49}$ SILVA, Sandoval Alves da. O Ministério Público e a concretização dos direitos humanos. Salvador: Juspodivm, 2016, p. 55.
} 
consistindo em manifesto descaso com as decisões meritórias ${ }^{50}$.

Para parte da doutrina, o princípio da cooperação, que envolve lealdade, probidade, boa-fé, colaboração mútua e cooperação, impõe os seguintes deveres ao juiz: a) conduzir o debate processual; b) esclarecer dúvidas quanto às alegações, aos pedidos e às posições; c) consultar as partes quanto ao que for decidir, assegurando o contraditório; d) prevenir, apontando às partes suas deficiências e franqueando-lhes a possibilidade de suprimento dessas deficiências ${ }^{51}$.

Em obediência à lealdade processual, há um dever de engajamento do juiz, sendo "dever do magistrado a condução do processo para um palco de discussão e interação constantes", porquanto "o processo passou a ser concebido como um palco deliberativo, um cenário de interações dialéticas que viabilizem o discurso argumentativo dos sujeitos envolvidos", impondo-lhe o dever de inserir-se nesse diálogo para que construam juntos a solução da causa ${ }^{52}$.

A análise do princípio cooperativo também é feita por quem entende o contraditório como obrigação de debate e de diálogo judiciário, dividindo-se assim os deveres cooperativos: a) dever de esclarecimento, que representa o dever do juiz de esclarecer aos demandantes as dúvidas que tenham sobre as alegações, os pedidos ou a posição em juízo; b) dever de prevenção, que envolve o dever de avisar acerca do perigo de o êxito dos pedidos ser frustrado pela utilização inadequada do processo; c) dever de consulta, que consiste no dever que o juiz tem de consultar os demandantes antes de decidir sobre qualquer questão, para permitir-lhes que exerçam influência na convicção a ser formada; d) dever de auxílio, que consiste no dever que o juiz tem de ajudar os demandantes na superação de eventuais dificuldades que impeçam o exercício de direitos, faculdades, cumprimento de ônus e deveres processuais ${ }^{53}$.

\footnotetext{
${ }^{50}$ FARIA, Marcio Carvalho. A lealdade processual na prestação jurisdicional: em busca de um modelo de juiz leal. São Paulo: Revista dos Tribunais, 2017, p. 412.

${ }^{51}$ CREMASCO, Suzana Santi. A distribuição dinâmica do ônus da prova. Rio de Janeiro: GZ, 2009, p. 8486.

${ }^{52}$ CABRAL, Antonio do Passo. Nulidades no processo moderno: contraditório, proteção da confiança e validade prima facie dos atos processuais. 2. ed. Rio de Janeiro: Forense, 2010, p. 227.

${ }^{53}$ MITIDIERO, Daniel Francisco. Colaboração no processo civil: pressupostos sociais, lógicos e éticos. 2. ed. São Paulo: Revista dos Tribunais, 2011. (Coleção Temas Atuais de Direito Processual Civil, v. 14), p. 8486.
} 
Registre-se o possível avanço por parte do TJPA referente ao engajamento ou à cooperação nas razões argumentativas do interessado e à preocupação com a realização da justiça material, tendo em vista o afastamento de possível "vício passivo" „54, que o Tribunal denominou "despacho de reserva". Com efeito, ao analisar Agravo de Instrumento em que se discutia a autorização para o funcionamento festivo de estabelecimento no período de férias, que estavam na iminência de acabar, o TJPA afastou o entendimento de $1 .^{\circ} \mathrm{Grau}$ (pela postergação de análise da liminar após a manifestação da autoridade coatora), que ensejaria a perda de objeto do remédio heroico. A Desembargadora Relatora analisou e deferiu o pleito de urgência ${ }^{55}$.

O neoconstitucionalismo representa a supremacia da Constituição, a valorização dos princípios e a constitucionalização do direito, bem como maior conteúdo material, atribuindo força normativa à Constituição e aos princípios. Além disso, o Judiciário desempenha um papel de destaque na implementação dos valores contidos na Constituição, que lhe garantiu expansão, a partir da positivação dos direitos fundamentais, segundo a corrente conceitualista. De fato, entende-se que o Judiciário foi favorecido pelo constitucionalismo brasileiro de efetividade, com a consolidação da democracia brasileira. Com o neoconstitucionalismo, a teoria dos princípios e a força normativa dada à Constituição, forneceu-se instrumento teórico para uma atuação ativista e maximalista, com razões amplas e profundas, contendo argumentos interdisciplinares ${ }^{56}$.

Ademais, exige-se uma sintonia entre Judiciário e Poder Público para a implantação de medidas judiciais, além de não se descartar uma dose razoável de accountability no Judiciário, tendo em vista a opinião popular. Deve-se observar a comunicação durante o processo de decisão - o process-accountability e a possível

\footnotetext{
${ }^{54}$ MENDES, Conrado Hübner. Direitos fundamentais, separação de poderes e deliberação. São Paulo: Saraiva, 2011, p. 242.

${ }^{55}$ TJPA (2. Turma de Direito Público). AI n. ${ }^{\circ}$ n. ${ }^{\circ}$ 0805840-30.2019.8.14.0000 no Mandado de Segurança n. ${ }^{\circ}$ 0837434-32.2019.8.14.0301, Relatora. Desa. Nadja Nara Cobra Meda. Data de Julgamento: 18/07/2019. Publicação 18/07/2019.

${ }^{56}$ BRANDÃO, Rodrigo. Supremacia judicial versus diálogos constitucionais: a quem cabe a última palavra sobre o sentido da Constituição? Rio de Janeiro: Lumen Juris, 2012, p. 60-61, p. 68, p. 136, p. 140 e p. 177.
} 
alteração das decisões no output-accountability -, acreditando-se que um modelo dialógico articula de maneira mais proveitosa a boa governança e os direitos fundamentais ${ }^{57}$.

Não se desconhecem as críticas à atuação maximalista do Judiciário, notadamente quando diante de casos altamente complexos, nos quais é recomendável a atuação minimalista para reduzir o risco de erro pelo Poder Judiciário ${ }^{58}$. Nessa linha de raciocínio, somam-se alguns argumentos que militam contra a atuação judicial maximalista, quais sejam: possível ilegitimidade democrática do Judiciário, necessidade de maior sensibilidade à opinião pública e chamada de outros atores para a boa interpretação da Constituição para produzir consensos ${ }^{59}$. Igualmente, há críticas à suposta ausência de qualidade deliberativa na Corte, dada a possível rigidez interpretativa, a verborragia e os "argumentos laterais sobre os cânones da argumentação jurídica, em vez de lidar com o dilema de fundo de modo franco e aberto" $"$.

A esse respeito, a teoria dos diálogos reconhece a falibilidade de todas as instituições, não admitindo a supremacia de uma delas. O que deve prevalecer é a interação complexa e dinâmica, inclusive com a sociedade civil ${ }^{61}$.

A propósito, um dos deveres do Judiciário é permitir o diálogo racional entre as partes litigantes, garantindo arranjos e disputas, assegurando visibilidade às diferentes reivindicações ${ }^{62}$. Com efeito, entre as capacidades institucionais do Judiciário, está a de promover um processo deliberativo guiado pela razão, observada a imparcialidade e a expertise em matéria jurídica, cabendo-lhe a primazia em questões de direitos fundamentais ${ }^{63}$.

\footnotetext{
${ }^{57}$ BRANDÃO, Rodrigo. Supremacia judicial versus diálogos constitucionais: a quem cabe a última palavra sobre o sentido da Constituição? Rio de Janeiro: Lumen Juris, 2012, p. 216, p. 221, p. 241, p. 270 e p. 288.

58 A atuação minimalista para alguns teóricos é defendida para os casos que estão sujeitos a circunstâncias mutáveis e a desacordo moral razoável, visto que tais casos caberiam ao Parlamento e não ao Judiciário (BRANDÃO, Rodrigo. Supremacia judicial versus diálogos constitucionais: a quem cabe a última palavra sobre o sentido da Constituição? Rio de Janeiro: Lumen Juris, 2012, p. 186).

${ }^{59}$ BRANDÃO, Rodrigo. Supremacia judicial versus diálogos constitucionais: a quem cabe a última palavra sobre o sentido da Constituição? Rio de Janeiro: Lumen Juris, 2012, p. 188 e p. 194.

${ }^{60}$ MENDES, Conrado Hübner. Direitos fundamentais, separação de poderes e deliberação. São Paulo: Saraiva, 2011, p. 102.

${ }^{61}$ BRANDÃO, Rodrigo. Supremacia judicial versus diálogos constitucionais: a quem cabe a última palavra sobre o sentido da Constituição? Rio de Janeiro: Lumen Juris, 2012, p. 208.

${ }^{62}$ LOPES, José Reinaldo de Lima. Direitos sociais: teoria e prática. São Paulo: Método, 2006, p. 138.

${ }^{63}$ BRANDÃO, Rodrigo. Supremacia judicial versus diálogos constitucionais: a quem cabe a última palavra sobre o sentido da Constituição? Rio de Janeiro: Lumen Juris, 2012, p. 203 e p. 223.
} 
O pluralismo e a hipercomplexidade das sociedades contemporâneas recomendam um acordo eventual e dinâmico, minimizando desacordos e viabilizando a estabilidade social. Por outro lado, a democracia deliberativa caracteriza-se pela justificação das razões, que devem ser públicas quanto à motivação e à deliberação, viabilizando-se um acordo com respeito ao pluralismo, não se pretendendo transformar o desacordo em acordo, mas, antes, buscar pontos em comum nas visões divergentes ${ }^{64}$.

O diálogo proporciona o enriquecimento epistêmico por meio de argumentos e cria um ônus de razão pública e deliberação. A deliberação guiada pela razão pública é uma variável dominante de legitimidade das decisões sobre direitos fundamentais ${ }^{65}$.

As teorias do diálogo buscam mitigar a tensão sobre a legitimidade substantiva procedimental da Corte na concretização dos direitos, prestigiando-se o "ativismo dialógico", com rodadas procedimentais e deliberativas em que se discutam alternativas para encontrar as medidas necessárias à concretização dos direitos fundamentais. Considerando as possíveis críticas ao accountability, não se descarta que tal exigência de prestação de contas judicial seja aferida de acordo com o atendimento das demandas sociais e a proteção do interesse público ${ }^{66}$.

Nos termos da teoria da parceria, diferentes vozes devem ser ouvidas. A flexibilidade da Constituição permite acomodar diversas interpretações, e o diálogo deliberativo é um instrumento de apresentação de razões substanciais pelos envolvidos, ao mesmo tempo que todos os atores discutem, o que possibilita a acomodação dos interesses concretizados, por meio da ampla participação e fundamentação ${ }^{67}$.

Frise-se que o diálogo permite o exercício da razão pública e o exercício da civilidade, refletindo um esforço para fazer da democracia não só um regime majoritário, mas também um mecanismo capaz de discernir bons e maus argumentos ${ }^{68}$.

\footnotetext{
${ }^{64}$ BRANDÃO, Rodrigo. Supremacia judicial versus diálogos constitucionais: a quem cabe a última palavra sobre o sentido da Constituição? Rio de Janeiro: Lumen Juris, 2012, p. 212-214.

${ }^{65}$ MENDES, Conrado Hübner. Direitos fundamentais, separação de poderes e deliberação. São Paulo: Saraiva, 2011, p. 213 e p. 232-233.

${ }^{66}$ SILVA, Sandoval Alves da. O Ministério Público e a concretização dos direitos humanos. Salvador: Juspodivm, 2016, p. 100 e p. 102.

${ }^{67}$ SILVA, Sandoval Alves da. O Ministério Público e a concretização dos direitos humanos. Salvador: Juspodivm, 2016, p. 139 e p. 168.

${ }^{68}$ SILVA, Sandoval Alves da. O Ministério Público e a concretização dos direitos humanos. Salvador: Juspodivm, 2016, p. 174.
} 
Por derradeiro, objetivando-se o enfrentamento do déficit de legitimidade, o diálogo viabiliza possível legitimidade no input - como o diálogo ocorre - e no output conteúdo ou substância do diálogo ${ }^{69}$.

Com efeito, pode-se extrair o possível prestígio do diálogo no procedimento especial do mandado de segurança, notadamente quando se prevê: a) a necessária intimação do Ministério Público para manifestação (art. 12 da LMS); b) a necessária oitiva prévia em caso de mandado de segurança coletivo (art. 22, § 2. ${ }^{\circ}$, da LMS); c) a permissibilidade de emenda da inicial (art. 321 do CPC c/c art. $6 .^{\circ}, \S 5 .^{\circ}$, da LMS); d) a eventual indicação errônea da autoridade coatora (Enunciados n. ${ }^{\circ} 42$ e n. ${ }^{\circ} 511$ do FPPC e n. ${ }^{o} 123$ do CJF) a minimizar a denegação indevida; e) a remessa necessária (art. $14, \S 1 .^{\circ}$, da LMS); f) a extensão do direito de recorrer à autoridade coatora (art. 14, § 2. ${ }^{\circ}$, da LMS); g) a intimação prévia do legitimado coletivo (pelo princípio do microssistema da tutela coletiva art. $5^{\circ}, \S 3 .^{\circ}$, da LACP) antes da extinção processual por ilegitimidade ativa ${ }^{70}$.

Nesse sentido, o TJPA adotou postura dialógica no MSC n. ${ }^{\circ}$ 080017986.2019.814.0124 em despacho de 2 de maio de 2019 que aplicou o artigo 321 do CPC, viabilizando a superação de irregularidade processual para eventualmente analisar adequadamente o mérito, embora tenha ocorrido superveniente desistência do mandamus em 28 de maio de 2019. Registra-se a postura do Tribunal, ainda que se saiba que esse não é o entendimento majoritário do TJPA, conforme exposto acima.

Assim, a ampliação do diálogo, permitindo que sejam apresentadas as diversas e melhores razões persuasivas e deliberativas pelos sujeitos envolvidos, tem o potencial de garantir maior legitimidade à apreciação do mérito e às decisões em mandado de segurança com a minimização das chances de erro do Judiciário. Por isso, a extinção terminativa por suposta ilegitimidade ou o julgamento de mérito com inadequada encampação devem ser evitados pelo Judiciário, a fim de permitir o diálogo processual.

\section{Conclusão}

${ }^{69}$ SILVA, Sandoval Alves da. O Ministério Público e a concretização dos direitos humanos. Salvador: Juspodivm, 2016, p. 183-184.

${ }^{70}$ Conforme ARAÚJO, Rodrigo Mendes de. A representação adequada nas ações coletivas. Salvador: Juspodium, 2013, p. 242. 
A superação de eventuais obstáculos processuais com a adoção de uma postura dialógica por parte do juiz no procedimento enseja o acesso à justiça pela apreciação do mérito com argumentos dos sujeitos envolvidos - direito social e, portanto, direito fundamental a ser concretizado, inclusive pelo Judiciário. $\mathrm{O}$ apego ao excessivo formalismo representa uma possível afronta à ordem renovatória de acesso à justiça e ao formalismo valorativo.

A adequada fundamentação da sentença é uma oportunidade que o Judiciário tem de prestar o devido accountability. Garantir essa prestação de contas viabiliza um melhor controle da atividade jurisdicional.

Ao lado disso, as soluções definitivas de mérito (evitando-se decisões terminativas) apresentam maior potencial de pacificação social, assegurando por meio do papel expansivo do Judiciário (sustentado na constitucionalização dos direitos fundamentais) o acesso à ordem jurídica justa, diminuindo conflitos e solucionando uma necessidade humana intermediária com a concretização dos direitos fundamentais por meio da racionalidade persuasiva e deliberativa que permite um engajamento do juiz e a lealdade da atividade jurisdicional.

O diálogo sob uma pespectiva deliberativa permite o exercício da razão pública e da civilidade com a viabilização de ampla participação e fundamentação.

A interação deliberativa minimiza o risco de erro e maximiza a chance do acerto, buscando melhores razões públicas.

Nesses termos, conforme demonstrado acima, os fundamentos para sustentar uma postura dialógica podem ser localizados no ordenamento positivo, como, por exemplo, nos artigos $6^{\circ}, 139$, IX, 317, 321, 338 e 339 do CPC/2015, mas a ele não se restringem, existindo, também, fundamentos filosóficos.

Aliás, o Judiciário paraense já adotou postura nesse sentido, notadamente ao julgar o MSC n. ${ }^{\circ}$ 0800179-86.2019.814.0124, decidindo pela aplicabilidade do artigo 321 do CPC ao procedimento especial do remédio heroico, embora esse não seja o entendimento majoritário da Corte Estadual, que tem concluído pela extinção terminativa do feito, em especial quando a substituição da autoridade coatora implicar alteração de competência. 
Diante disso, ainda que momentaneamente não se admita dilação probatória no mandado de segurança, entende-se cabível a postura dialógica nesse procedimento especial como forma de melhor tutelar os direitos fundamentais, garantindo-se a superação de eventuais irregularidades processuais e permitindo-se um maior engajamento ou cooperação a) do juiz diante das manifestações dos sujeitos adequadamente representados (tanto do impetrante eventualmente corrigido pelo princípio do microssistema coletivo art. 5..$^{\circ}$ § $3 .^{\circ}$, da LACP c/c art. 321 do CPC - quanto da autoridade coatora, diante dos arts. 338 e 339 do CPC e art. 14, § 2. ${ }^{\circ}$, da LMS), b) da Fazenda Pública (art. 7. ${ }^{\circ}$, II, da LMS) e c) do Ministério Público (art. 12, da LMS), por meio da persuasão racional plural e viabilizando a prestação jurisdicional mais adequada, qualitativa, legítima e leal.

Assim, com base na análise do direito positivo e em fundamentos filosóficos e teóricos do diálogo, entende-se que não só é possível como é necessário que seja priorizada e efetivamente praticada a postura dialógica procedimental na solução e na tutela dos direitos fundamentais, inclusive no remédio heroico, viabilizando-se a legitimação democrática procedimental, com a participação efetiva dos sujeitos envolvidos, e a legitimação decisória, com a prestação dos melhores esclarecimentos e argumentos que permitam o adequado engajamento judicial referente ao conteúdo da decisão judicial.

\section{REFERÊNCIAS Bibliográficas}

ALEXY, Robert. Teoria dos direitos fundamentais. São Paulo: Malheiros, 2008.

ANDRADE, Igor Ascarelli Castro de. Constituição e desigualdade em John Rawls. Belo Horizonte: Editora D’Plácido, 2018.

ARAÚJO, José Henrique Mouta. Mandado de segurança. 6. ed. Salvador: Juspodivm, 2017.

ARAÚJO, Rodrigo Mendes de. A representação adequada nas ações coletivas. Salvador: Juspodium, 2013.

BRANDÃO, Rodrigo. Supremacia judicial versus diálogos constitucionais: a quem cabe a última palavra sobre o sentido da Constituição? Rio de Janeiro: Lumen Juris, 2012. 
CABRAL, Antonio do Passo. Nulidades no processo moderno: contraditório, proteção da confiança e validade prima facie dos atos processuais. 2. ed. Rio de Janeiro: Forense, 2010

CAMBI, Eduardo. Neoconstitucionalismo e neoprocessualismo. Revista do Programa de Pós-Graduação em Direito da Universidade Federal da Bahia, Salvador, n. 17, p. 93-130, 2008.2.

CAPPELLETTI, Mauro. Juízes legisladores? Tradução de Carlos Alberto Alvaro de Oliveira. Porto Alegre: Sergio Antonio Fabris, 1993.

CREMASCO, Suzana Santi. A distribuição dinâmica do ônus da prova. Rio de Janeiro: GZ, 2009.

DIDIER JR., Fredie; ZANETI JR., Hermes. Curso de Direito Processual Civil: processo coletivo. 12. ed. São Paulo: Juspodivm, 2017.

DOYAL, Len; GOUGH, Ian. Una teoría de las necesidades humanas. Barcelona: Icaria, 1994.

FARIA, Marcio Carvalho. A lealdade processual na prestação jurisdicional: em busca de um modelo de juiz leal. São Paulo: Revista dos Tribunais, 2017.

FISS, Owen. Modelos de adjudicação. Caderno de Direito GV, São Paulo, v. 1, n. 8, p. 357, nov. 2005.

HEINEN, Juliano. Interesse público: premissas teórico-dogmáticas e proposta de fixação de cânones interpretativos. Salvador: Juspodivm, 2018.

JESUS, Thiago Vasconcellos. O princípio da cooperação e contraditório no MS: a aplicação dos arts. 338 e 339 do CPC/15 no procedimento especial do MS e possíveis benefícios processuais. Trabalho apresentado no XLIV Congresso Nacional de Procuradores do Estado e do Distrito Federal. Salvador, 2018.

LOPES, José Reinaldo de Lima. Direitos sociais: teoria e prática. São Paulo: Método, 2006.

MENDES, Conrado Hübner. Direitos fundamentais, separação de poderes e deliberação. São Paulo: Saraiva, 2011.

MITIDIERO, Daniel Francisco. Colaboração no processo civil: pressupostos sociais, lógicos e éticos. 2. ed. São Paulo: Revista dos Tribunais, 2011. (Coleção Temas Atuais de Direito Processual Civil, v. 14). 
OLIVEIRA, Carlos Alberto Alvaro de. O formalismo-valorativo no confronto com o formalismo excessivo. Revista da Faculdade de Direito da UFRGS, Porto Alegre, $\mathrm{n}$. 26, p. 60-88, 2006.

SEN, Amartya. A ideia de justiça. Tradução de Denise Bottmann e Ricardo Doninelli Mendes. São Paulo: Companhia das Letras, 2011.

SILVA, Sandoval Alves da. Direitos sociais: leis orçamentárias como instrumento de implementação. Curitiba: Juruá, 2007.

SILVA, Sandoval Alves da. O Ministério Público e a concretização dos direitos humanos. Salvador: Juspodivm, 2016.

SILVA, Sandoval Alves da. O (in)acesso à justiça social com a demolidora reforma trabalhista. In: MIESSA, Élisson; CORREIA, Henrique. (Org.). A reforma trabalhista e seus impactos. Salvador: Juspodivm, 2017. v. 1, p. 1075-1103.

SOKAL, Guilherme Jales. A teoria da encampação no mandado de segurança. Trabalho apresentado no XXXIX Congresso Nacional de Procuradores do Estado e do Distrito Federal. Porto de Galinhas, 2013. 